\section{Urinary Hydroxyproline and Thyroid} Disease

SIR,-Measurement of the 24-hour urinary excretion of hydroxyproline as an index of the disturbed collagen metabolism found in thyroid disease and the use of this measurement as a test of thyroid function have been previously described. ${ }^{12}$ The changes found were increased excretion in hyperthyroidism and decreased excretion in hypothyroidism, these changes being present in some $70-90 \%$ of adults with thyrotoxicosis, ${ }^{12}$ and some $70 \%$ of adults with hypothyroidism. ${ }^{1}$ It was concluded that these tests were useful in the diagnosis of thyroid disease in adults, particularly in thyrotoxicosis.

In view of the inconvenience and difficulty of collecting 24-hour urine samples it was decided to investigate the reliability of using random urine samples and expressing the results in terms of $\mathrm{mg}$ hydroxyproline per $\mathrm{g}$ creatinine.

The patients studied were all adults being investigated for possible thyroid disease, but excluding patients known to have other conditions which might be associated with changes in collagen metabolism. The thyroid status of the patients was assessed in all cases by history and clinical examination together with the determination of serum thyroxine iodine. ${ }^{3}$ In most cases radioiodine uptake tests and a triiodothyronine uptake test ${ }^{4}$ were also performed. On the basis of all the available information 50 patients were classified as euthyroid, 18 as hyperthyroid, and 6 as hypothyroid.

Random urine samples, taken on the same day as the blood samples for in-vitro thyroid function tests were analysed for total hydroxyproline $^{5}$ and creatinine. 6 The patients were not asked to restrict their intake of gelatin-containing foods prior to the collection of urine samples, but samples were collected between 9 a.m. and 6 p.m. to exclude early morning and nocturnal samples (see below).

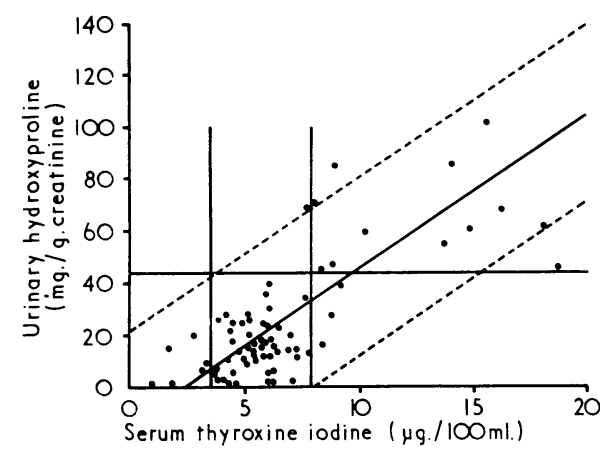

Relationship between urinary hyroxyproline excretion and serum thyroxine iodine. Closed circles show values in euthyroid patients, open circles
values in patients with thyroid disease. The horizontal line represents the upper limit of normal for hydroxyproline excretion and the vertical lines the normal range for thyroxine iodine. The oblique lines show the regression line $\pm 2 S$.D.

The normal and abnormal ranges for serum thyroxine iodine (corrected for $75 \%$ recovery) were as follows: euthyroid $3.5-8.0 \mu \mathrm{g} / 100 \mathrm{ml}$, hypothyroid $<4.0 \mu \mathrm{g} / 100 \mathrm{ml}$, and hyperthyroid $>7.5 \mu \mathrm{g} / 100 \mathrm{ml}$. The normal range for hydroxyproline in random urine samples was taken as less than $42 \mathrm{mg} / \mathrm{g}$ creatinine. This was done because although the normal range for 24-hour urinary hydroxyproline in this laboratory is $6-42 \mathrm{mg} / \mathrm{g}$ creatinine, it was found that five of the euthyroid patients had random hydroxyproline levels below $2 \mathrm{mg} / \mathrm{g}$ creatinine. This finding is probably related to the time of collection of the samples and the known circadian rhythm of hydroxyproline excretion, the rate being lowest at or soon after midday.

It was found that of the 18 patients classified as thyrotoxic only three had hydroxyproline values within the normal range. These normal values may have been associated with the fact that these patients had only moderately raised serum thyroxine iodine levels, all being between 8.0 and $9.0 \mu \mathrm{g} / 100 \mathrm{ml}$, or may have been due to the time of day at which the urine samples were collected. The absence of a lower limit of normal for hydroxyproline values in the euthyroid patients precluded the test in this form from being of any value in the diagnosis of hypothyroidism, but the mean level in the small hypothyroid group, $8.6 \mathrm{mg} / \mathrm{g}$ creatinine, was markedly lower than the mean level for the euthyroid group, $15.0 \mathrm{mg} / \mathrm{g}$ creatinine.

A significant positive correlation between 24-hour urinary total hydroxyproline excretion and serum protein bound iodine in adults has previously been reported. ${ }^{2}$ The figure shows the correlation between total hydroxyproline in random urine samples and serum thyroxine iodine levels in the 74 patients examined in this series. Analysis showed the correlation to be highly significant $(r=+0.82, p<0.001)$ and further analysis by the method of least squares gave a regression line of: Hydroxyproline $(\mathrm{mg} / \mathrm{g}$ creatinine) $=6.04 \times$ thyroxine iodine $(\mu \mathrm{g} / 100 \mathrm{ml})-14.6$. The standard deviation (1S.D.) on the line is $\pm 17.5 \mathrm{mg} / \mathrm{g}$ creatinine.

It is concluded that estimation of the hydroxyproline content of random urine samples is a useful ancillary test in the diagnosis of hyperthyroidism, giving as good separation of abnormal from normal as has been reported for the 24-hour test. ${ }^{2}$ It is also concluded that the test in this form is, for the reasons discussed, of no value in the diagnosis of hypothyroidism. It must be stressed that this test is not a specific test of thyroid function and that consequently the results must be interpreted with caution in patients who also have other diseases which may be associated with disturbed collagen metabolism.

We would like to thank the physicians in the Bristol clinical area who have been kind enough to allow us to study patients under their care.-We are, etc.,

\section{J. Goldie} C. A. PENNOCK

Department of Chemical Pathology,
United Bristol Hospitals

Uitto, J., Laitinen, O., Lamberg, B.-A., and 22,583 . 22, 583.
(Kergenhavn), 1970, Suppl. No. 146, p. 23. Murphy, B. P., Fournal of Laboratory and Clinical Medicine, 1965, 66, 161.

Herbert, V., Gottlieb, C. W., Lau, K. S., Gilbert
P., and Silver, S., fournal of Laboratory and Clinical Medicine, 1965, 66, 814

Pennock, C. A., Moore, G. R., and Hoyle, M. D. fournal of

6 Technicon Method File N-11.

Mautalen, C. A., fournal of Laboratory and
Clinical Medicine, 1970, 75, 11 .

\section{G.M.C. Finances}

SIR,-The General Medical Council has recently reminded us sharply of its lack of funds and proposes further financial levies.

In the past, many of us have felt that lack of business acumen and prudent housekeeping had much to do with the parlous financial state in which the General Medical Council finds itself. We all hoped it would have remedied this, after the recent scrutiny of its financial arrangements.

But alas, this is not so.

Following the policy of the British Medical Association agreed at the Special Representative Meeting last spring (Supplement, 21 February), I paid my donation this year on 25 October to the General Medical Council. Despite its vast overdraft it took a month to pay my $£ 2$ into the bank. I have enquired among my friends and it appears that the same dilatory attitude applies to the cheques of others. I would have thought that any properly run organization with an overdraft such as the General Medical Council runs would be along to the bank every day to pay in the money received as soon as it comes in.-I am, etc.,

Welwyn Garden City,
Herts

J. S. Ross

\section{Platelet Transfusions}

SIR,-Is it the climate? Or is it the angle from which we view things in the Antipodes? Your excellent succint leading article on platelet transfusions (2 January, p. 2) states that the dose for the treatment of thrombocytopenia comprises the platelet concentrates from ten donors twice weekly, but makes no mention of the technical work involved in preparing these concentrates. Our good friend Dr. R. A. Cumming and others (2 January, p. 50) in the correspondence columns of the same issue laments the ignorance of clinicians (their Antipodean counterparts are similary uninformed) concerning the logistics of blood banking, but unfortunately omitted the details of the technical load. Yet if one starts with ten donations of blood collected without any interruption to the flow rate, as even microclots consume platelets, and provided a special centrifuge is available, it takes the equivalent of three accident-free technologist man-hours to carry out the necessary centrifugings and transfers of plasma to produce ten platelet concentrates.

However, two donations of blood less than 36 hours old, or the platelet rich plasma from five donations, if administered within 1-1 $\frac{1}{2}$ hours, will produce the same therapeutic result as that obtained from the use of ten platelet concentrates in partial correction of thrombocytopenia, with the added bonus of partial correction of the severe leucopenia which often results from the use of "ablative" chemotherapy in the treatment of leukaemia. Circulatory overload can be avoided if a half litre of blood is removed from the patient before use of the citrated blood or platelet-rich plasma.

This technique, reported ${ }^{1}$ in 1969 (and subsequently the subject of an annotation in the Lancet $^{2}$ ) has been used successfully in Queensland and elsewhere for the past three years. It has a particular advantage in avoiding iron overload in the patient requiring prolonged treatment with twice-weekly withdrawls of half a litre of blood and alternate administration of a litre of blood or five platelet-rich plasma units. Currently the saving in our service-which caters for the needs of a population of nearly 2,000,000- 